\title{
Comparative Analysis of Fuzzy/ANN Techniques for Compensation of Unbalanced Voltages in Grid Connected PMSG Based Wind Turbine
}

\author{
U.Sri Anjaneyulu ${ }^{1}$, T.Satish Babu' ${ }^{2}$,Y.Narendra Kumar ${ }^{3}$ \\ Assistant professor ${ }^{1,2}$, Professor ${ }^{3}$, Department of EEE ${ }^{1,2,3}$ \\ Lendi Institute of Engineering and Technology, Vizianagaram, Andhra Pradesh, India \\ Email:sri0255@gmail.com ${ }^{1}$, satishthatithuri@gmail.com ${ }^{2}$
}

\begin{abstract}
This paper proposes an effective controller for grid connected wind turbine based permanent magnet synchronous machine for improving unbalanced voltages. In this paper, we proposed a comparative analysis under different controllers like PI, Fuzzy and Artificial Neural Network Controller to PMSG system. A control structure is designed based on the positive sequence reference signals. With the help of these controllers, the double frequency oscillations in DC-link voltages and variations in active power can be eliminated. More ever, the proposed system can be implemented in Matlab/Simulink and the performance of the proposed Grid based PMSG wind system under grid fault conditions is verified.
\end{abstract}

Keywords— PMSG, Wind Turbine, PI, Fuzzy, ANN, Grid-system.

\section{INTRODUCTION}

Lately, many new breeze farms make use of wind turbines predicated on permanent magnet synchronous machine. This wind turbine based synchronous generators have been increasing demand in the industrial areas. The studies on the control strategies of PMSG under asymmetrical and symmetrical grid faults have become one of the key research sections of the wind power technology development.

In the present scenario, for protecting the system from these problems several control strategy have been introduced. In, predicated on the examination of the dc-link voltage distortions under unbalanced grid voltages, this paper proposed an average dual PI current control strategy predicated on negative and positive series part decomposition. The operational system structure is organic, which is difficult to adapt control parameters. In, an up-to-date control design using proportional controller was suggested to control the negative and positive series components current of the grid--side converter (GSC), that are integrated in the stationary reference framework?

Generally, permanent magnet synchronous machine is commonly used for wind turbine because of it rigid construction. The configuration of the proposed integrated grid and WECS based PMSG are first introduced in this paper [1]. Main constraints in general wind turbine are steady-state operating conditions under various wind speeds and marinecurrent speeds and the dynamic stability of the studied system. An RSC and GSC converters are introduced for improving the steady state and dynamic stability with the designed PI damping controller under different operating conditions. In this paper the controlling of PMSG is verified by using artificial neural network (ANN), Fuzzy logic controller.

\section{ARCHITECTURE OF PROPOSED GRID CONNECTED WIND SYSTEM \\ 2.1. Grid Integration}

1. Reactive power capability: the successful wind forms generally maintain the power factor over a range of approximately 0.95 .

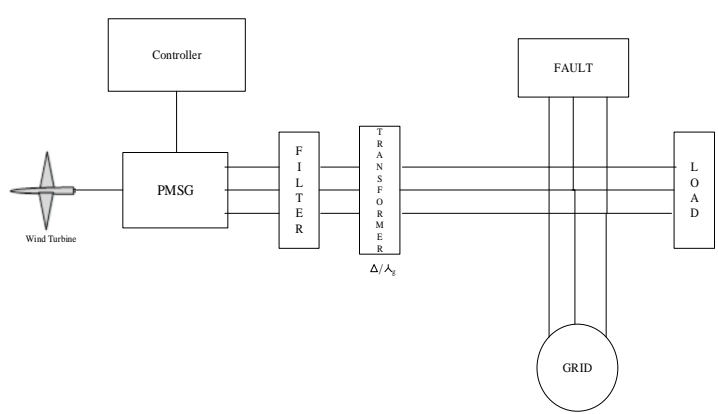

Fig. 1: Hybrid System

In this paper a PMSG based WECS hybrid system with various controllers is considered, sustaining power to a load and the network as appeared in Figure 1. The turbine coupling shaft is demonstrated as one mass drive framework as the appraised rotor rate is low with a higher number of rotor poles for the PMSG.

\subsection{Wind Turbine}

Wind turbines are basically classified into two types, Horizontal and Vertical axis. A vertical axis machine has its blades rotating on an axis perpendicular to the bottom. There square measure variety of obtainable styles for each and every kind has bound benefits and downsides. 


\section{Available online at www.ijrat.org}

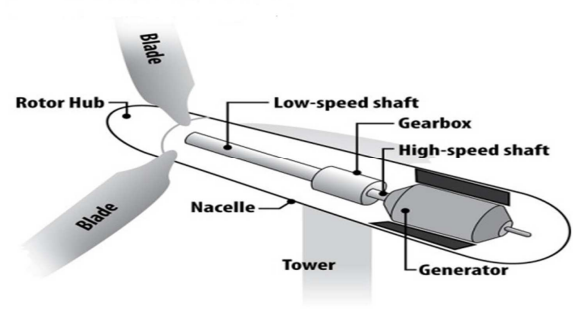

Fig. 2: Basic diagram of wind turbine

\subsection{Architecture of PMSG}

A synchronous machine is generally a rotating machine whose steady state speed is proportional to frequency of the armature current. The basic structure of the permanent magnet synchronous machine for wind system is shown in figure 3. Generally, PMSG machines are two types such as cylindrical and salient rotor types. The operational modes of PMSM is decided by the sign of electro-mechanical torque (such as $+\mathrm{Ve}$ sign for motoring operation and $-\mathrm{Ve}$ sign represents generating condition). For modelling PMSM machine the electrical and mechanical parts are indicated in the form of state space analysis. In case of PMSM machine the stator flux produced by the permanent magnet is always sinusoidal [6].

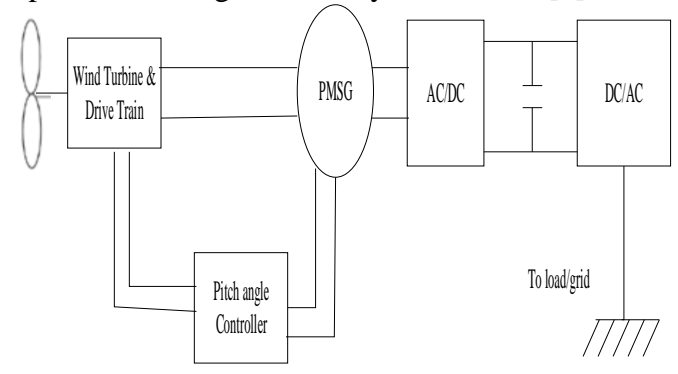

Fig. 3: Structure of Permanent Magnet Synchronous Machine in Wind Turbine

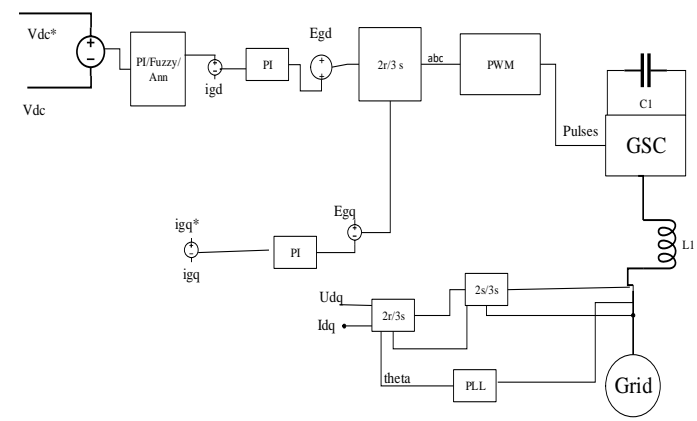

Fig. 4 PMSG Control Diagram

The control strategy for the PMSG machine is shown in figure 4 . This control structure is designed by the help of d-q transformation technique. A general PI controller is used in this paper for controlling unbalanced voltages.

\subsection{PI Controller}

A PI (proportional-integral) controller is a combination of proportional and integral controller which is used for eliminating steady state error and peak overshoots. The absence of derivative controller shows more stability under noise conditions. This is because the derivative controller is more sensitive under high frequency systems [8].

The general expression for PI controller is expressed as,

$$
K_{P} \Delta+K_{I} \int \Delta d t
$$

\subsection{Fuzzy Logic Controller}

In the previous section, control strategy based on PI controller is discussed. But in case of PI controller, it has high settling time and has large steady state error. In order to rectify this problem, this paper proposes the application of a fuzzy controller shown in Figure 5. Generally, the FLC is one of the most important software based technique in adaptive methods.

As compared with previous controllers, the FLC has low settling time, low steady state errors. The operation of fuzzy controller can be explained in four steps.

1. Fuzzification

2. Membership function

3. Rule-base formation

4. Defuzzification

In this paper, the membership function is considered as a type in triangular membership function and method for defuzzification is considered as centroid. The error which is obtained from the comparison of reference and actual values is given to fuzzy inference engine. The input variables such as error and error rate are expressed in terms of fuzzy set with the linguistic terms VN, N, Z, P, and Pin this type of mamdani fuzzy inference system the linguistic terms are expressed using triangular membership functions.

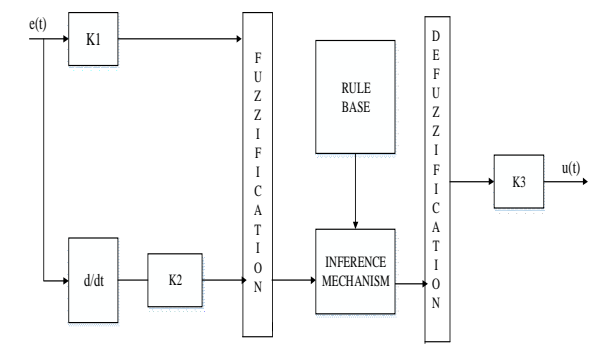

Fig. 5: Basic structure of fuzzy logic controller

In this paper, single input and single output fuzzy inference system is considered. The number of linguistic variables for input and output is assumed as 3.The numbers of rules are formed as 9.The input for the fuzzy system is represented as error of PI controller. The fuzzy rules are obtained with if-then statements. The given fuzzy inference system is a combination of single input and single output. This input is related with the logical operator AND/OR operators. AND logic gives the output as minimum 


\section{Available online at www.ijrat.org}

value of the input and OR logic produces the output as maximum value of input.

\subsection{Artificial Neural Networks}

Figure 6 shows the basic architecture of artificial neural network, in which an hidden layer is indicated by circle, an adaptive node is represented by square. In this structure hidden layers are presented in between input and output layer, these nodes are functioning as membership functions and the rules obtained based on the if-then statements is eliminated. For simplicity, we considering the examined ANN have two inputs and one output. In this network, each neuron and each element of the input vector $\mathrm{p}$ are connected with weight matrix $\mathrm{W}$.

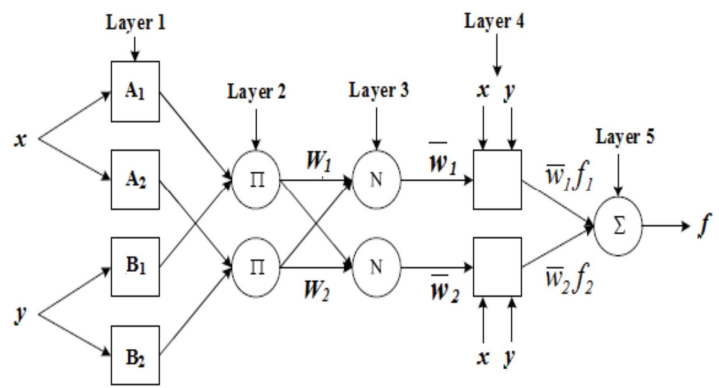

Fig. 6: ANN architecture for a two-input multi-layer network

Where the two crisp inputs are $\mathrm{x}$ and $\mathrm{y}$, the linguistic variables associated with the node function are $\mathrm{Ai}$ and $\mathrm{Bi}$. The system has a total of five layers are shown in Figure 6.

Step by step procedure for implementing ANN:

1. Identify the number of input and outputs in the normalized manner in the range of 0-1.

2. Assume number of input stages.

3. Identify number of hidden layers.

4. By using transig and poslin commands create a feed forward network.

5. Assume the learning rate should be 0.02 .

6. Choose the number of iterations.

7. Choose goal and train the system.

8. Generate the simulation block by using 'genism' command.

\section{SIMULATION DIAGRAM \& RESULT}

Simulation review of proposed PMSG wind mill was completed using Simulink Library. The PMSG was making rated active GSC and power was working with unity electric power factor. Figure 7-14 shows the performance waveforms for the proposed system under different fault conditions. The GSC controller is verified by different controller (PI/Fuzzy/Ann) to attain better performance level under two cases.

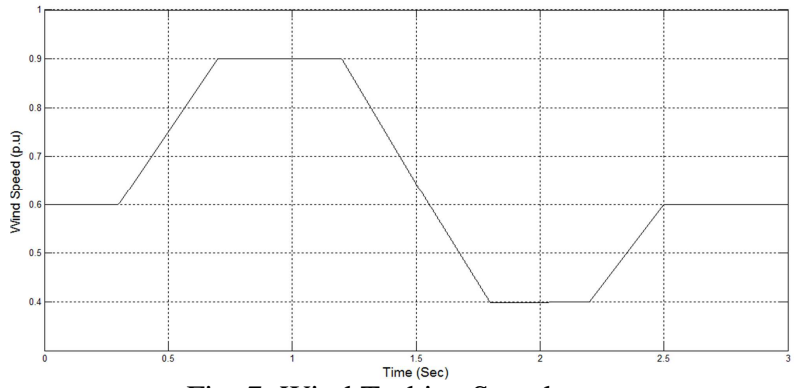

Fig. 7: Wind Turbine Speed

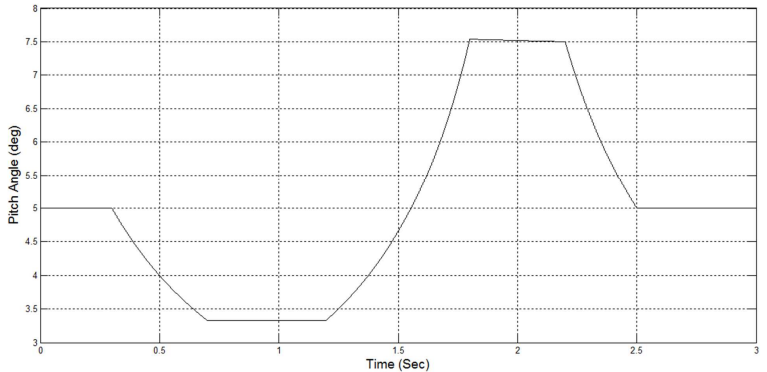

Fig. 8: Wind Turbine pitch anle

Case 1: Single Phase to Ground Fault

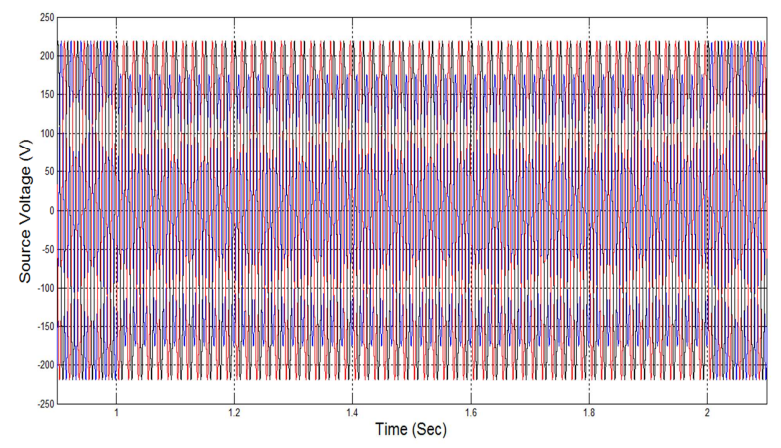

Fig, 9: Three Phase Grid Volatge Under L-G Fault

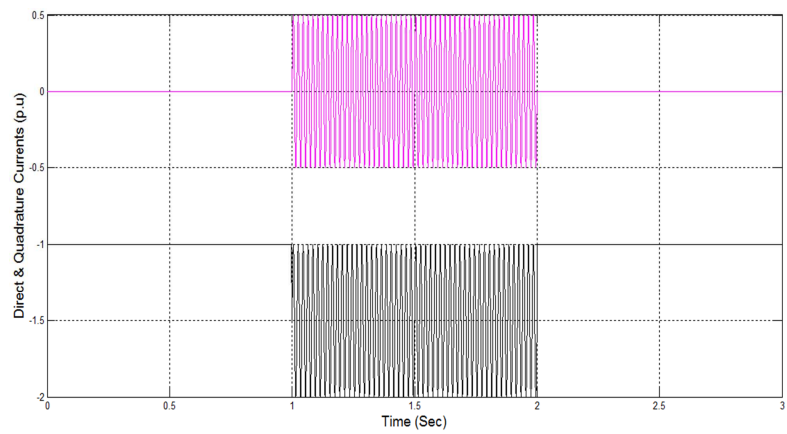

Fig. 10: Direct and Quadrature Currents Under L-G

Fault 
International Journal of Research in Advent Technology, Vol.7, No.4S, April 2019 E-ISSN: 2321-9637

Available online at www.ijrat.org

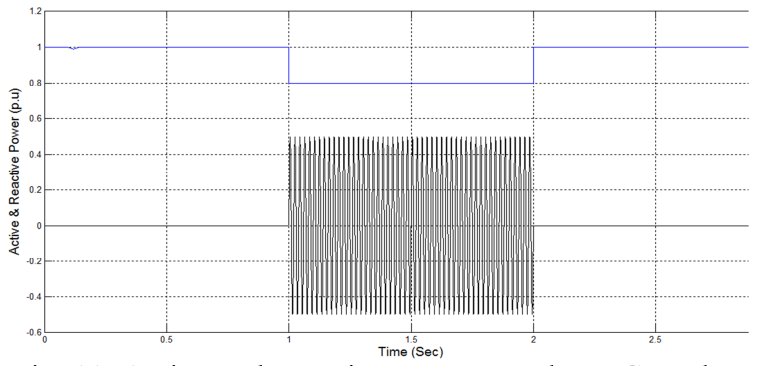

Fig. 11: Active and Reactive Powers Under L-G Fault

Case 2: Three Phase Fault

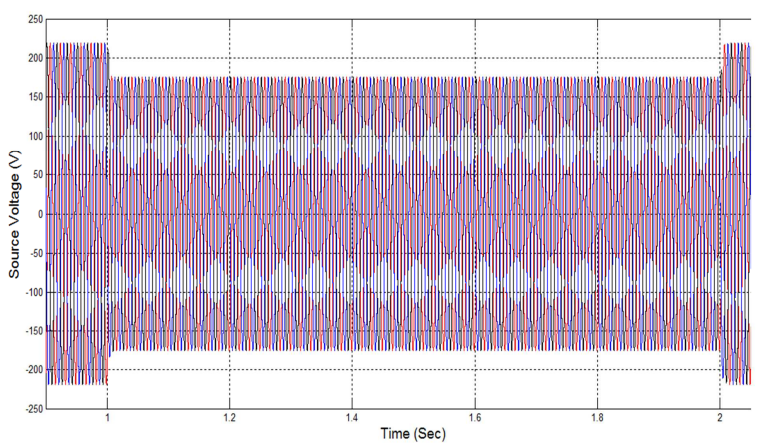

Fig. 12: Three Phase Grid Volatge Under Three Phase Fault

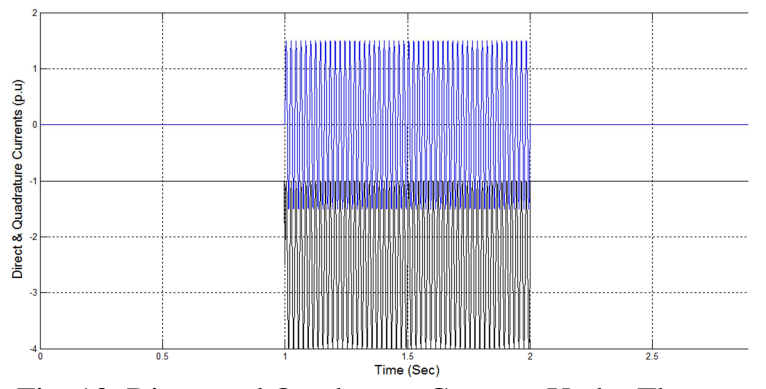

Fig. 13: Direct and Quadrature Currents Under Three Phase Fault

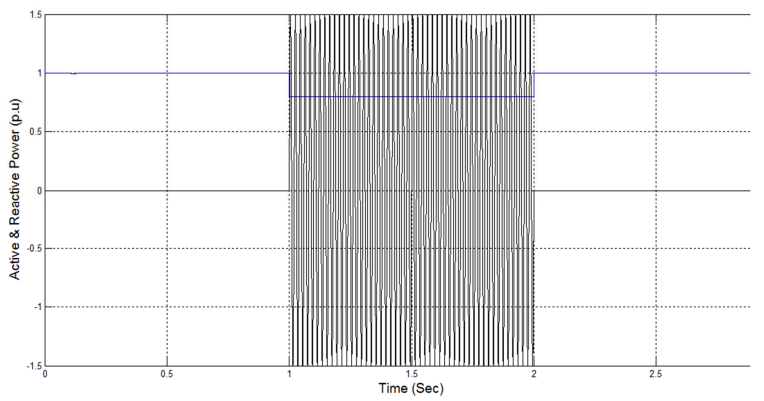

Fig. 14: Active and Reactive Powers Under Three Phase Fault

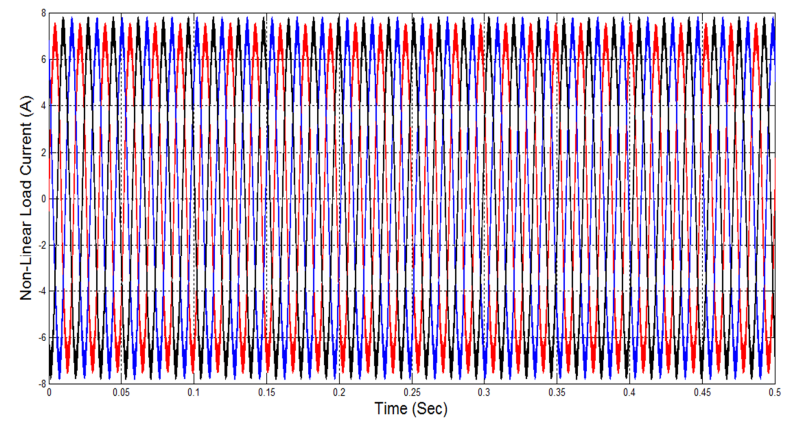

Fig. 15: Non-Linear Load Current

Analysis of Total Harmonic Distrotion for Load Current:

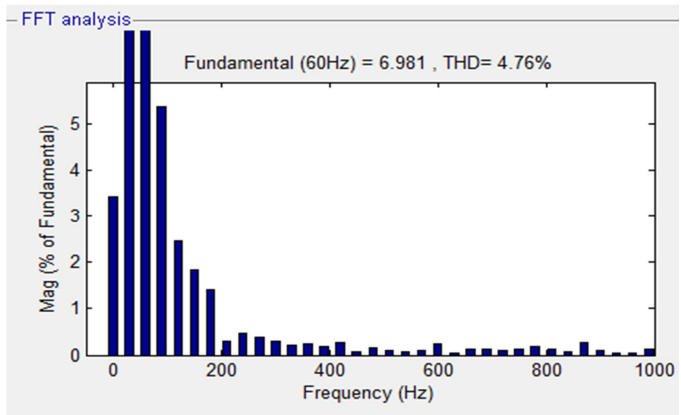

Fig. 16: Analysis of THD with PI Controller

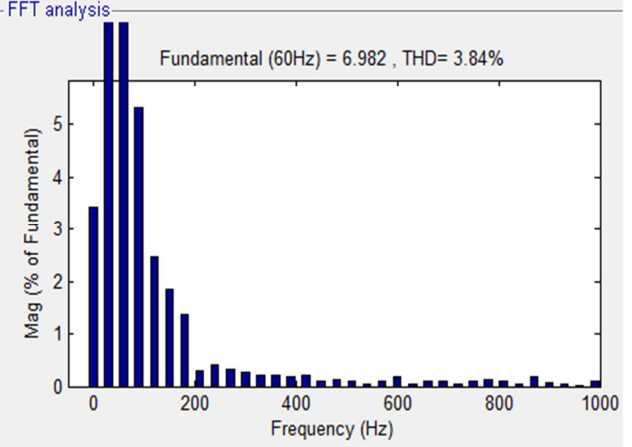

Fig. 17: Analysis of THD with Fuzzy Controller

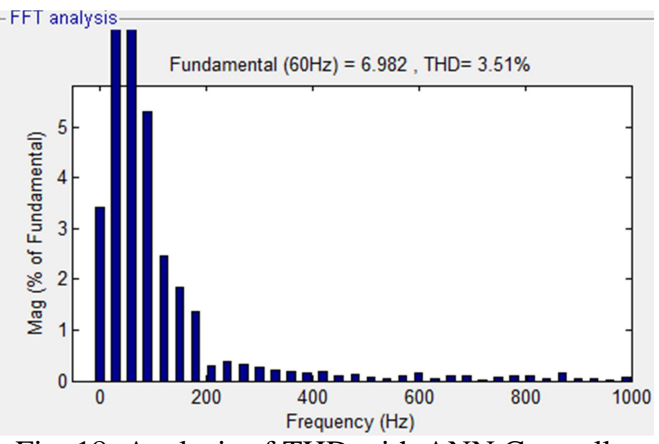

Fig. 18: Analysis of THD with ANN Controller

\section{CONCLUSION}

This paper proposed a different (PI/Fuzzy/ANN) control techniques for Converter which is used in 


\section{Available online at www.ijrat.org}

PMSG for reducing unbalanced voltage conditions. For restraining the oscillation components, this paper proposed an controller with positive reference synchronous frame coordinators as reference signals. As a total result, the suggested ANN-based control strategy is easy without any decomposition and complicated research calculation. From the simulation results and harmonic distrotion factor, we conclude that the neuro controller shows the better result as compared to fuzzy and PI controllers.

\section{REFERENCES}

[1] Shuhui Dong,Yonggang Li,Aimeng Wang, Wenyuan Xi, "Control of PMSG Wind Turbines Based on Reduced Order Resonant Controllers Under Unbalanced Grid Voltage Conditions" IEEE PEDS 2015, Sydney, Australia 9 - 12 June 2015.

[2] Ng, C.H, Ran, L, Bumby, J, "Unbalanced-GridFault Ride-Through Control for a Wind Turbine Inverter[J]" IEEE Transactions on Industry Applications, 2008, 44(3): 845-856.

[3] Yin Bo , Oruganti R , Panda S K, et al, “ An output-powercontrol strategy for a three-phase PWM rectifier under unbalanced supply conditions [J" IEEE Transactions on Industrial Electronics, 2008, 55(5): 2140-2151.

[4] Hu Jiabing, He Yikang, "Modeling and control of grid-connected voltage-sourced converters under generalized unbalanced operation conditions[J]", IEEE Transactions on Energy Conversion, 2008, 23(3): 903-913.

[5] Etxeberria-Otadui I, Viscarret U, Caballero M , et al, "New optimized PWM VSC control structures and strategies under unbalanced voltage transients[J]" IEEE Transactions on Industrial Electronics, 2007, 54(5): 2902-2914.

[6] Yao Jun, Chen Xiyin, Liao Yong, LiHui, Huang Song, " A Grid-Connection Control Strategy to Suppress Negative-Sequence and Harmonic Currents for Permanent Magnet Direct-Driven Wind Power Generation System [J]", Power System Technology, 2011, 35(7): 29-35.

[7] Busada C A, Gomez J S, Leon, A E, et al, "Current controller based on reduced order generalized integrators for distributed generation systems[J]", IEEE Transactions on Industrial Electronics, 2012, 59(7): 2898-2909.

[8] ZHAO Xin, JIN Xinmin, ZHOU Fei, LI Geliang, "Unbalanced Control of Grid-Connected Inverters Based on Proportion Integral Reduced Order Resonant Controllers[J]", Proceedings of the CSEE, 2013, 33(19): 84-92 